\title{
Desempenho de animais alimentados com lâminas foliares, em pastagem de capim-marandu
}

\author{
Luís Armando Zago Machado(1), Amoacy Carvalho Fabrício(1), Alberto Gomes ${ }^{(2)}$, Paulo Giovani Gall De Assis ${ }^{(2)}$, \\ Beatriz Lempp ${ }^{(3)}$ e Gerzy Ernesto Maraschin ${ }^{(4)}$
}

(1)Embrapa Agropecuária Oeste, Caixa Postal 661, CEP 79804-970 Dourados, MS. E-mail: zago@cpao.embrapa.br, amoacy@cpao.embrapa.br
(2)Embrapa Gado de Corte, Caixa Postal 154, CEP 79002-970 Campo Grande, MS. E-mail: gomes@cnpgc.embrapa.br, giovani@cpao.embrapa.br
(3)Universidade Federal da Grande Dourados, Caixa Postal 533, CEP 79804-970 Dourados, MS. E-mail: blempp@ufgd.edu.br (4)Fundação
Estadual de Pesquisa Agropecuária do Rio Grande do Sul, Caixa Postal 44, CEP 90130-060 Porto Alegre, RS. E-mail: gerzy@terra.com.br

Resumo - O objetivo deste trabalho foi avaliar o desempenho de animais, alimentados com lâminas de folhas verdes (LFV) a 4, 8, 12 e 16\% do peso vivo por dia, em pastagens de capim-marandu. O experimento foi conduzido em delineamento de blocos ao acaso, com duas repetições. A avaliação do desempenho dos novilhos $F_{1}$ Nelore e Charolês foi realizada de outubro de 2002 a junho de 2005, nas estações das águas, em Dourados, MS. Cada unidade experimental foi pastejada em regime de pastejo contínuo e carga animal variável, com quatro animais traçadores que permaneceram no experimento dos 15 aos 23 meses de idade, quando foram abatidos. Foi obtido efeito linear entre as ofertas pretendidas e as observadas. A consistência da ingestão de folhas verdes, independentemente das ofertas, foi evidenciada em novilhos fistulados no esôfago. O ganho médio diário apresentou resposta quadrática às ofertas de LFV, com máximo resultado com a oferta de $11,7 \%$ do peso vivo. A carga animal e o ganho por hectare apresentaram resposta quadrática negativa ao aumento das ofertas. As ofertas de 8 a $12 \%$ do peso vivo permitem que os animais consumam as folhas verdes, com boa qualidade da dieta.

Termos para indexação: Brachiaria brizantha, carga animal, consumo de folha verde, ganho por animal, oferta de forragem.

\section{Performance of animals fed with green leaf in marandu grass pasture}

Abstract - The objective of this work was to evaluate the performance of animals, fed with green leaves at 4 , 8,12 and $16 \%$ of live weight per day, in marandu grass pastures. The experimental design was in complete randomized blocks, with two replications. Animal performance evaluations were made from October 2002 to June 2005, with steers $F_{1}$ Nelore and Charolais, along the rainy seasons, in Dourados County, Mato Grosso do Sul, Brazil. Four tester animals - 15 to 23 months old - grazed each experimental unit, under continuous grazing and put-and-take technique; the animals were, afterwards, slaughtered. Linear effect was obtained for the intended and observed forage allowances. The consistency of green leaf ingestions by the animals (independently of the offers) was evidenced in esophagus-fistulated steers. The average daily gain showed quadratic response in relation to the green leaf offers, with its optimum level at $11.7 \%$ live weight. Stoking rate and live weight gain per hectare presented a negative quadratic effect to the increase of blade dry matter offers. The offers of 8 to $12 \%$ live weight allow animals to feed on green leaf blades and to have a good quality diet.

Index terms: Brachiaria brizantha, stocking rate, green leaf intake, daily gain, forage offer.

\section{Introdução}

$\mathrm{Na}$ Região dos Cerrados encontra-se mais da metade da produção nacional de carne bovina, e cerca de $80 \%$ de suas pastagens apresentam algum estágio de degradação (Barcellos, 1996), de cujas causas destacam-se: manejo inadequado, falta de adubação de manutenção, erros na formação, cobertura e sistema radicular deficientes, pragas, doenças e plantas daninhas (Muller et al., 2001; Peron \& Evangelista, 2004).

Quanto ao manejo inadequado, a utilização de taxas de lotação superiores à capacidade de suporte das pastagens gera o superpastejo, que causa prejuízos à taxa de rebrota das forrageiras, reduz a disponibilidade de forragem e compromete o desempenho dos animais 
(Machado \& Kichel, 2004). A adequação da taxa de lotação pode evitar ou retardar a degradação das pastagens, com pouco ou nenhum impacto no custo de produção.

No estudo da relação planta-animal, podem-se fixar alguns fatores tais como taxa de lotação, massa de forragem pré e pós-pastejo e oferta de forragem. A taxa de lotação tem influência no desempenho animal, mas ao se comparar apenas esta variável, pode-se incorrer em erro, já que ela tem relação com outros fatores (Sollenberger et al., 2005). Fatores ambientais aliados ao manejo de pastagem podem determinar diferentes massas de forragem e estruturas do dossel. A ingestão de nutrientes e o desempenho de animais em pastejo são afetados pelas modificações da estrutura do dossel (Trindade et al., 2007).

O uso de lotação variável é outra forma de estudar esta relação, quando se fixa a massa de forragem ou a altura do relvado. Esse método permite minimizar variações decorrentes da flutuação da massa de forragem, que é um problema quando se utiliza taxa de lotação fixa.

$\mathrm{O}$ fator que permite avaliar, com segurança, o desempenho animal em pastagem é a oferta de forragem, por integrar informações da massa de forragem e taxa de lotação (Sollenberger et al., 2005). O uso de oferta de forragem fixa e taxa de lotação variável foi um método desenvolvido em condição de clima temperado (Mott \& Lucas, 1952). Maraschin \& Mott (1989) verificaram que, ao se expressar a oferta de forragem em percentagem do peso vivo, se poderia facilitar o entendimento de pressões de pastejo nos experimentos com animais.

Nas regiões temperadas, onde foram desenvolvidos os primeiros estudos sobre oferta de forragem, as alterações na densidade de forragem são lentas, e as frações colmo e material senescente são menos expressivas do que nos trópicos, porque as gramíneas $\mathrm{C}_{3}$ não alongam os entrenós no estádio vegetativo, como as gramíneas $\mathrm{C}_{4}$ (Sollenberger \& Moore, 1997).

Dos componentes da forragem, a fração folhas apresenta a melhor qualidade e representa mais de $80 \%$ da dieta (Forbes \& Hodgson, 1985). O consumo de forragem é otimizado quando a oferta de forragem é maior que três a quatro vezes a capacidade de ingestão dos animais (Gibb \& Treacher, 1976; Hodgson, 1984). Portanto, para as pastagens tropicais, convém considerar a oferta de massa de matéria seca de lâminas de folhas verdes, para se estimar a taxa de lotação e avaliar com maior precisão o desempenho dos animais. Heringer \& Carvalho (2002) propõem, ainda, que no cálculo da carga animal seja considerada a perda de forragem, como uma forma de se aumentar a precisão do ajuste.

Em capim-elefante cultivar Mott, sob pastejo contínuo, Almeida et al. (2000a, 200b) observaram que a oferta de lâminas foliares de $11,3 \%$ do peso vivo permitiu máximo ganho, por animal, e assegurou a condição de sustentabilidade da pastagem. Segundo Barbosa et al. (2006), para Panicum maximum cultivar Tanzânia, em pastejo contínuo e taxa de lotação variável, a oferta de forragem de lâminas foliares verdes - mais condizente para a associação entre ganho médio diário, ganho por hectare e dinâmica do perfilhamento - foi entre 7 e $11 \%$.

Embora a Brachiaria brizantha seja a principal espécie utilizada nas pastagens brasileiras, faltam estudos que relacionem oferta de forragem com o desempenho animal.

O objetivo deste trabalho foi avaliar o desempenho de animais, em pastagens de Brachiaria brizantha cultivar Marandu, submetidos a quatro ofertas de matéria seca de lâminas de folhas verdes.

\section{Material e Métodos}

O experimento de pastejo foi conduzido na Embrapa Agropecuária Oeste, Dourados, MS, $\left(22^{\circ} 14\right.$ 'S e $54^{\circ} 49^{\prime} \mathrm{W}$, latitude de $430 \mathrm{~m}$ ). A pastagem de Brachiaria brizantha cultivar Marandu foi semeada em fevereiro de 2001, em Latossolo Vermelho distroférrico, mantido há mais de 20 anos com culturas anuais, principalmente soja que, segundo análise, apresentou os seguintes resultados: $\mathrm{pH} \mathrm{CaCl}{ }_{2}, 4,7 ; \mathrm{Al}, 0,28 \mathrm{cmol}_{\mathrm{c}} \mathrm{dm}^{-3} ; \mathrm{Ca}$, $3,8 \mathrm{cmol}_{\mathrm{c}} \mathrm{dm}^{-3} ; \mathrm{Mg}, 1,7 \mathrm{cmol}_{\mathrm{c}} \mathrm{dm}^{-3} ; \mathrm{K}, 0,6 \mathrm{cmol}_{\mathrm{c}} \mathrm{dm}^{-3}$; $\mathrm{P}, 6,5 \mathrm{mg} \mathrm{dm}^{-3} ; \mathrm{V}, 46,2 \%$ e MO, $31,8 \mathrm{~g} \mathrm{~kg}^{-1}$.

Os tratamentos corresponderam às ofertas de matéria seca de lâminas de folhas verdes. $\mathrm{O}$ delineamento experimental utilizado foi o de blocos ao acaso, com parcelas subdivididas no tempo, com duas repetições. De janeiro a julho de 2002, foram utilizadas as ofertas pretendidas de 5, 8, 11 e 14\% (quilogramas de lâminas foliares verdes por $100 \mathrm{~kg}$ de peso vivo por dia); e de outubro de 2002 a maio de 2003, outubro de 2003 a junho de 2004 e novembro de 2004 a junho de 2005, foram utilizadas as ofertas de 4, 8, 12 e $16 \%$ do peso vivo. $\mathrm{Na}$ troca de ofertas, não ocorreram mudanças 
de área. As áreas dos piquetes foram 1,5, 1,7, 2,5 e 3 ha, para as ofertas de $4,8,12$ e $16 \%$ do peso vivo, respectivamente.

Nos períodos 2002/2003 e 2003/2004, foram aplicados $150 \mathrm{~kg} \mathrm{ha}^{-1}$ de $\mathrm{N}$, em três parcelas de $50 \mathrm{~kg} \mathrm{ha}^{-1}$ (outubro, dezembro e fevereiro). De $2004 \mathrm{a}$ 2005 , foram aplicados somente $100 \mathrm{~kg} \mathrm{ha}^{-1} \mathrm{de} \mathrm{N}$, pois em fevereiro ocorreu deficit hídrico (Figura 1).

Para a avaliação do desempenho, foram utilizados novilhos $F_{1}$, resultantes do cruzamento das raças Nelore e Charolês. Na primeira estação seca, entre a desmama e o início do experimento, os animais permaneceram em pastagem de capim-marandu, suplementados com sal proteinado. Os animais foram castrados aos 13 meses, e permaneceram no experimento dos 15 aos 23 meses de idade. Os pesos médios dos animais no início do experimento, foram de 265,284 e $302 \mathrm{~kg}$, nos períodos 2002/2003, 2003/2004 e 2004/2005, respectivamente.

$\mathrm{O}$ método de pastejo utilizado foi o contínuo, com carga animal variável, ajustada mensalmente de acordo com a disponibilidade de matéria seca de lâminas foliares verdes, pela técnica "put-and-take" (Mott \& Lucas, 1952). Em cada unidade experimental, havia quatro animais traçadores e um número variável de animais reguladores, que foram pesados sob jejum de 14-16 horas, em intervalos de 28 dias.

A coleta de amostras da forragem em oferta e da extrusa foram realizadas a cada 35 dias, de novembro de 2002 a maio de 2003. Da forragem em oferta, foram cortados quatro quadrados de $0,50 \times 0,50 \mathrm{~m}$, ao longo de duas transectas aleatórias, por piquete, tendo-se realizado o corte a $10 \mathrm{~cm}$ do solo. Após a pesagem, retirou-se uma subamostra de $10 \%$ do peso, para a separação dos componentes morfológicos, que foi processada para a estimativa do teor de matéria seca (MS). As amostras da extrusa foram obtidas de dois bovinos fistulados no esôfago, por piquete, no período da manhã. As bolsas para coleta da extrusa foram colocadas antes de os animais entrarem nos piquetes experimentais e foram retiradas logo após o seu enchimento parcial. As amostras de extrusa foram separadas em lâminas e colmo, e secadas em estufa para as análises químicas.

As amostras das lâminas foliares da forragem em oferta e da extrusa foram utilizadas para a análise da composição química e da digestibilidade in vitro da matéria orgânica, por meio de espectrofotometria de refletância no infravermelho proximal (NIRS). O NIRS foi calibrado para análise de: proteína bruta
(Association of Official Analytical Chemists, 1990); fibra em detergente ácido e neutro (Goering \& Van Soest, 1970); lignina (Goering \& Van Soest, 1970); e digestibilidade in vitro da matéria orgânica (Tilley \& Terry, 1963).

$\mathrm{O}$ ajuste de carga animal foi realizado a cada 28 dias, com base na massa de lâminas foliares verdes existente, somada ao acúmulo diário de lâminas foliares verdes do período anterior, e projetada para o período seguinte. A massa de lâminas foliares verdes foi estimada pelo método de rendimento comparativo (Haydock \& Shaw, 1975), e o acúmulo pelo método agronômico, tendo-se utilizado a dupla amostragem, com uso de gaiolas de exclusão do pastejo. As variáveis referentes à pastagem estão disponíveis em Machado et al. (2007). A carga animal diária para se alcançar a oferta pretendida foi calculada pela equação: carga animal $=100$ (massa de lâminas foliares verdes + acúmulo de lâminas foliares verdes)/oferta de lâminas foliares verdes, em que a carga animal foi estimada em quilogramas por hectare de peso vivo; a massa de lâminas foliares verdes e o acúmulo de lâminas foliares verdes foram expressas em quilogramas por hectare por dia; e a oferta, a quantidade de lâminas foliares verdes por $100 \mathrm{~kg}$ de peso vivo por dia, foi expressa em percentagem do peso vivo.

A carga animal efetiva foi obtida pelo somatório dos pesos de todos os animais, traçadores e reguladores, presentes num determinado período (28 dias), dividido pela área do piquete, expressa em quilograma de peso vivo por hectare. A carga média dividida pelo peso médio dos animais traçadores forneceu o número de animais por dia por hectare.

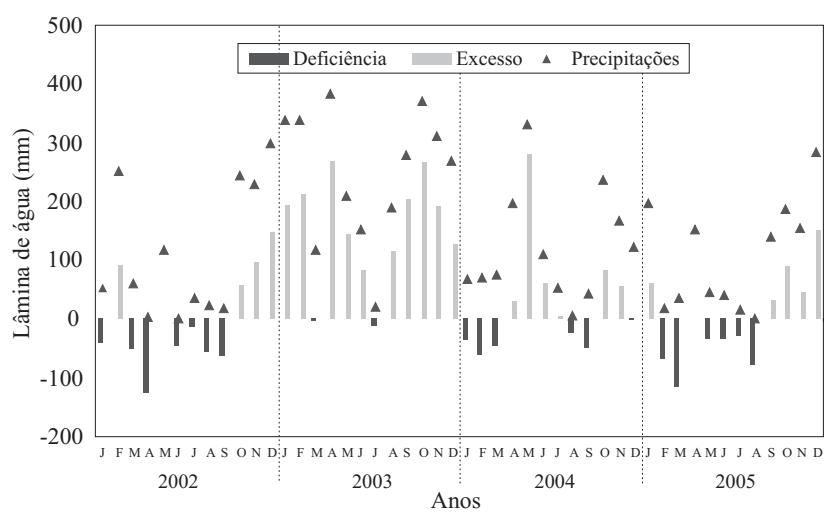

Figura 1. Balanço hídrico seqüencial de 2002 a 2005, em Dourados, MS. 
O ganho de peso médio diário dos animais traçadores foi obtido pela diferença entre as pesagens realizadas, no início e no final de cada período experimental, dividido pelo número de dias transcorridos entre as avaliações, expresso em quilograma por animal por dia. O ganho de peso por hectare foi determinado pela multiplicação do ganho médio diário dos animais traçadores pelo número de animais por dia por hectare, expresso em quilograma de peso vivo por hectare.

Para a análise estatística, foram utilizadas as médias de cada variável. Cada ponto nos gráficos equivale à média da unidade experimental e do ano, considerando-se os pontos de amostragem em cada unidade e os meses avaliados, respectivamente. Os resultados foram submetidos ao teste $\mathrm{F}$, e as regressões foram ajustadas tendo-se utilizado como variável independente as ofertas de lâminas foliares verdes. As análises foram realizadas com auxílio do programa SigmaPlot 8.0 (Systat Software, 2002). Para a comparação de médias entre os tratamentos, nas variáveis qualitativas, utilizou-se o teste SNK (Student-Newman-Keuls), a $5 \%$ de probabilidade.

\section{Resultados e Discussão}

As ofertas de lâminas foliares verdes pretendidas e observadas apresentaram correlação significativa $(\mathrm{p}<0,05)$, e variou de 4 a 16 e de 3 a $15 \mathrm{~kg}$ por $100 \mathrm{~kg}$ de peso vivo, respectivamente (Figura 2). A oferta observada foi um pouco inferior à pretendida, em razão do método utilizado de estimativa do acúmulo de lâminas foliares verdes (método agronômico), e em razão dos períodos de deficit hídrico (Figura 1).

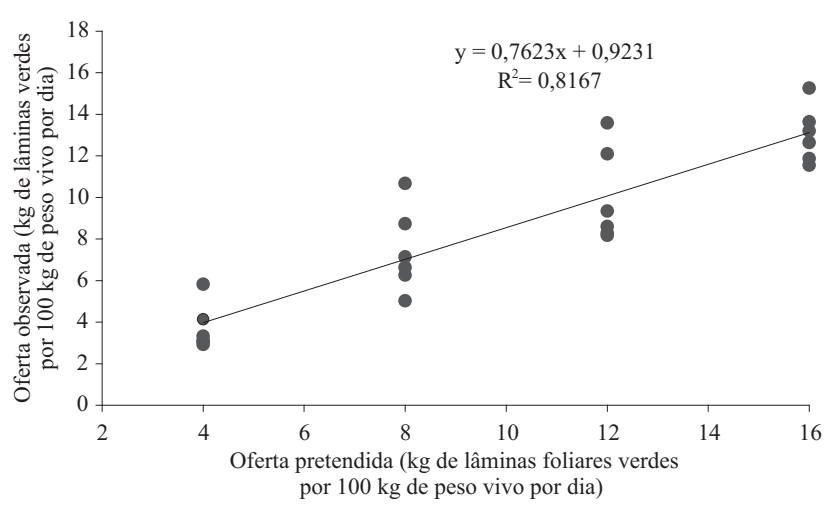

Figura 2. Ofertas de matéria seca de lâminas foliares verdes pretendidas e observadas, em pastagem de capimmarandu, nas estações das águas de 2002/2003, 2003/2004 e $2004 / 2005$.
Para o cálculo da carga animal, tomou-se como base a massa de lâminas foliares verdes, obtida ao final do período de 28 dias de pastejo, somada ao acúmulo de lâminas foliares verdes do período imediatamente anterior (obtida em gaiola de exclusão) e projetada para os 28 dias seguintes. Ocorreram secas intensas nos verões de 2004 e 2005, o que causou em menores taxas de acúmulo, em relação aos anos normais. Assim, as cargas animais pretendidas foram superestimadas, porque as taxas de acúmulo projetadas foram maiores do que as observadas.

O manejo dos piquetes, na oferta de $4 \%$ de lâminas foliares verdes, resultou em maior teor de proteína bruta e digestibilidade in vitro da matéria orgânica, e menor teor de fibra em detergente ácido, nas lâminas foliares da forragem oferecida, em relação às demais ofertas (Tabela 1), e não interferiu nos teores de fibra em detergente neutro e lignina das lâminas em oferta, que foram em média de 70,8 e 8,1\%, respectivamente. $\mathrm{O}$ teor de fibra em detergente neutro observado foi inferior ao indicado por Mertens (1996), acima do qual pode ocorrer limitação no consumo. Observou-se que as baixas ofertas de lâminas foliares verdes comprometem o desempenho animal, por reduzirem o consumo de forragem que, segundo Poppi et al. (1987) e Dalley et al. (1999), está relacionado à oferta.

Os animais em pastejo selecionam a forragem de melhor qualidade e colhem preferencialmente as folhas

Tabela 1. Teores de proteína bruta (PB), fibra em detergente neutro (FDN), fibra em detergente ácido (FDA), lignina (LIG) e digestibilidade in vitro da matéria orgânica (DIVMO) de lâminas foliares da forragem em oferta de capim-marandu e da extrusa, em quatro ofertas de lâminas foliares ${ }^{(1)}$.

\begin{tabular}{|c|c|c|c|c|c|}
\hline \multirow[t]{2}{*}{ Teores } & \multicolumn{4}{|c|}{$\begin{array}{l}\text { Oferta de matéria seca de lâminas } \\
\text { foliares verdes }(\% \mathrm{PV})\end{array}$} & \multirow[t]{2}{*}{$\mathrm{CV}(\%)$} \\
\hline & 4 & 8 & 12 & 16 & \\
\hline & \multicolumn{5}{|c|}{ Lâminas da forragem } \\
\hline $\mathrm{PB}(\% \mathrm{MS})$ & $13,7 \mathrm{a}$ & $9,7 b$ & $10,7 b$ & $9,8 b$ & 18,0 \\
\hline FDN (\%MS) & $68,0 \mathrm{a}$ & $71,4 \mathrm{a}$ & $71,7 \mathrm{a}$ & $71,9 a$ & 3,1 \\
\hline FDA (\%MS) & $34,0 \mathrm{~b}$ & $36,5 \mathrm{a}$ & $36,8 \mathrm{a}$ & $37,2 \mathrm{a}$ & 5,2 \\
\hline $\mathrm{LIG}^{(2)}(\% \mathrm{MS})$ & $8,0 \mathrm{a}$ & $8,1 \mathrm{a}$ & $8,2 \mathrm{a}$ & $8,0 \mathrm{a}$ & 9,9 \\
\hline \multirow[t]{2}{*}{ DIVMO (\%MS) } & $66,6 \mathrm{a}$ & $59,4 \mathrm{~b}$ & $59,7 \mathrm{~b}$ & $58,6 \mathrm{~b}$ & 8,1 \\
\hline & \multicolumn{5}{|c|}{ Lâminas da extrusa } \\
\hline PB (\%MS) & $13,9 \mathrm{a}$ & $12,5 b$ & $12,6 b$ & $12,8 \mathrm{~b}$ & 9,4 \\
\hline FDN (\%MS) & $70,4 \mathrm{~b}$ & $73,6 \mathrm{a}$ & $73,0 \mathrm{a}$ & $72,9 \mathrm{a}$ & 3,1 \\
\hline $\mathrm{LIG}^{(2)}(\% \mathrm{MS})$ & $7,3 \mathrm{a}$ & $6,1 b$ & $5,6 b$ & $5,7 b$ & 22,0 \\
\hline DIVMO (\%MS) & $58,1 \mathrm{a}$ & $59,0 \mathrm{a}$ & $60,0 \mathrm{a}$ & $59,8 \mathrm{a}$ & 4,8 \\
\hline
\end{tabular}

${ }^{(1)}$ Médias seguidas de letras diferentes, na linha, diferem entre si pelo teste de SNK, a 5\% de probabilidade. ${ }^{(2)}$ Lignina em permanganato de potássio. 
(Van Soest, 1994). Isto foi observado em todas as ofertas estudadas (Tabela 2). Pela composição química obtida com as lâminas foliares da extrusa (Tabela 1), observou-se que os animais ingeriram melhor a forragem com a oferta de $4 \%$ de lâminas foliares verdes, em virtude dos maiores teores de proteína bruta e menores de fibra em detergente neutro nesse tratamento. Entretanto, nessa oferta, os teores de lignina foram significativamente superiores, o que pode comprometer mais a qualidade do que as diferenças em proteína bruta e fibra em detergente neutro. De acordo com Mertens (1996), de 60 a $90 \%$ da variação na qualidade das forrageiras são atribuídos às diferenças no consumo.

Dos componentes orgânicos da parede celular, a lignina é o polímero que reconhecidamente limita a digestão dos polissacarídeos da parede celular no rúmen (Grabber, 2005) e, conseqüentemente, o consumo e o desempenho animal. O baixo teor de carboidratos não estruturais e a alta resistência da parede celular à digestão ruminal também contribuem para o menor fluxo duodenal de proteína da forragem e microbiana (Doyle, 1987). Então, com gramíneas tropicais pode ocorrer a deficiência de aminoácidos no intestino, com prejuízo ao desempenho animal (Kempton \& Leng, 1979). Na oferta de $4 \%$ de lâminas foliares verdes, as lâminas da extrusa apresentaram maior teor de lignina, em relação aos demais, talvez pela menor oportunidade de pastejo seletivo. Mas os valores observados de

Tabela 2. Proporção de matéria seca de lâminas foliares verdes da forragem em oferta de capim-marandu e da extrusa, em quatro ofertas de lâminas foliares verdes, de dezembro de 2002 a maio de $2003^{(1)}$.

\begin{tabular}{|c|c|c|c|c|c|}
\hline \multirow[t]{2}{*}{ Meses } & \multicolumn{4}{|c|}{$\begin{array}{l}\text { Oferta de matéria seca de lâminas } \\
\text { foliares verdes }(\% \mathrm{PV})\end{array}$} & \multirow[t]{2}{*}{ CV $(\%)$} \\
\hline & 4 & 8 & 12 & 16 & \\
\hline \multicolumn{6}{|c|}{ Lâminas da forragem } \\
\hline Dezembro & $33,6 \mathrm{aB}$ & $53,1 \mathrm{aA}$ & $50,5 \mathrm{aA}$ & $53,6 \mathrm{aA}$ & 9,9 \\
\hline Janeiro & $32,5 \mathrm{aA}$ & $42,4 \mathrm{bA}$ & $35,8 \mathrm{bA}$ & $42,7 \mathrm{bA}$ & 15,3 \\
\hline Fevereiro & $17,3 \mathrm{bB}$ & $15,8 \mathrm{cB}$ & $16,9 \mathrm{cB}$ & $24,5 \mathrm{cA}$ & 20,4 \\
\hline Março & $31,9 \mathrm{aA}$ & $20,0 \mathrm{cB}$ & $22,3 \mathrm{cB}$ & $27,4 \mathrm{cAB}$ & 18,4 \\
\hline Maio & $25,6 \mathrm{abA}$ & $14,5 \mathrm{cA}$ & $18,3 \mathrm{cA}$ & $18,7 \mathrm{cA}$ & 28,9 \\
\hline \multicolumn{6}{|c|}{ Lâminas da extrusa } \\
\hline Dezembro & $97,4 \mathrm{aA}$ & $98,1 \mathrm{aA}$ & $99,2 \mathrm{aA}$ & $99,1 \mathrm{aA}$ & 1,3 \\
\hline Janeiro & $99,0 \mathrm{aA}$ & $99,5 \mathrm{aA}$ & $97,8 \mathrm{aA}$ & $98,2 \mathrm{aA}$ & 1,4 \\
\hline Fevereiro & $99,2 \mathrm{aA}$ & $98,0 \mathrm{aAB}$ & $97,6 \mathrm{aAB}$ & $95,8 \mathrm{bB}$ & 1,2 \\
\hline Março & $98,8 \mathrm{aA}$ & $98,2 \mathrm{aA}$ & $99,1 \mathrm{aA}$ & $99,1 \mathrm{aA}$ & 0,8 \\
\hline Maio & $97,6 \mathrm{aA}$ & $98,8 \mathrm{aA}$ & $99,3 \mathrm{aA}$ & $98,8 \mathrm{aA}$ & 1,2 \\
\hline
\end{tabular}

${ }^{(1)}$ Médias seguidas de letras diferentes, minúsculas na coluna e maiúsculas na linha, diferem entre si pelo teste de SNK, a 5\% de probabilidade. lignina na extrusa foram inferiores aos da forragem em oferta, e decresceram a partir da oferta de $8 \%$ de lâminas foliares verdes, nas áreas onde poderia ocorrer pastejo seletivo.

Com relação à fibra em detergente ácido, ocorreu interação $(p<0,01)$ entre oferta e período. Nos meses de dezembro de 2002, janeiro, fevereiro e março de 2003, os teores de fibra em detergente ácido foram semelhantes com as ofertas de 4 e $8 \%$, em média $37,6 \%$, e superiores $(\mathrm{p}<0,05)$ aos obtidos com 12 e $16 \%$ de lâminas foliares verdes, em média $35,3 \%$. A oferta da forragem não interferiu nos teores de fibra em detergente ácido, em maio, com média de 35,1\%.

A composição química das lâminas em oferta e da extrusa variou em função do período (Tabela 3). As lâminas em oferta presente apresentaram teores de proteína bruta inferior em março de 2003 e, nos demais meses, a média foi de $11,6 \%$; no entanto, os animais colheram dieta com teores acima de $12 \%$, em todos os períodos, o que, segundo o National Research Council (1996) não restringe o ganho em peso de bovinos de corte. Nas lâminas em oferta foi observada a menor digestibilidade in vitro da matéria orgânica, em fevereiro e março de 2003, e não ocorreram diferenças na digestibilidade in vitro da matéria orgânica das lâminas da extrusa, entre os períodos avaliados. Em dezembro de 2002, as lâminas em oferta apresentaram valores que expressaram maior qualidade, em relação aos demais períodos avaliados.

Tabela 3. Teores de proteína bruta (PB), fibra em detergente neutro (FDN), fibra em detergente ácido (FDA), lignina (LIG) e digestibilidade in vitro da matéria orgânica (DIVMO), de lâminas foliares verdes da forragem em oferta de capim-marandu e da extrusa, de dezembro de 2002 a maio de $2003^{(1)}$.

\begin{tabular}{lcccccc}
\hline Teores & Dez. & Jan. & Fev. & Mar. & Maio CV (\%) \\
\hline \multicolumn{7}{c}{ Lâminas da forragem } \\
PB (\%MS) & $12,3 \mathrm{a}$ & $12,3 \mathrm{a}$ & $10,6 \mathrm{a}$ & $8,5 \mathrm{~b}$ & $11,2 \mathrm{a}$ & 18,0 \\
FDN (\%MS) & $70,3 \mathrm{bc}$ & $71,8 \mathrm{ab}$ & $68,8 \mathrm{c}$ & $72,5 \mathrm{a}$ & $70,3 \mathrm{bc}$ & 5,2 \\
FDA (\%MS) & $33,4 \mathrm{~d}$ & $35,1 \mathrm{c}$ & $36,9 \mathrm{~b}$ & $39,9 \mathrm{a}$ & $35,3 \mathrm{~b}$ & 3,1 \\
LIG $^{(2)}(\% \mathrm{MS})$ & $6,9 \mathrm{c}$ & $8,0 \mathrm{~b}$ & $8,1 \mathrm{~b}$ & $9,0 \mathrm{a}$ & $8,5 \mathrm{ab}$ & 9,9 \\
DIVMO (\%MS) & $67,2 \mathrm{a}$ & $65,0 \mathrm{a}$ & $57,8 \mathrm{~b}$ & $52,3 \mathrm{c}$ & $63,1 \mathrm{a}$ & 8,1 \\
\hline \multicolumn{7}{c}{ Lâminas da extrusa } \\
PB (\%MS) & $12,3 \mathrm{~b}$ & $13,0 \mathrm{a}$ & $12,8 \mathrm{ab}$ & $13,7 \mathrm{a}$ & $12,9 \mathrm{ab}$ & 9,4 \\
FDN (\%MS) & $72,5 \mathrm{a}$ & $73,7 \mathrm{a}$ & $72,1 \mathrm{a}$ & $72,2 \mathrm{a}$ & $71,9 \mathrm{a}$ & 3,1 \\
LIG $^{(2)}(\% \mathrm{MS})$ & $5,3 \mathrm{~b}$ & $5,6 \mathrm{ab}$ & $6,4 \mathrm{ab}$ & $6,8 \mathrm{a}$ & $6,7 \mathrm{a}$ & 22,0 \\
DIVMO (\%MS) & $59,4 \mathrm{a}$ & $57,6 \mathrm{a}$ & $60,7 \mathrm{a}$ & $60,2 \mathrm{a}$ & $58,9 \mathrm{a}$ & 6,2 \\
\hline
\end{tabular}

${ }^{(1)}$ Médias seguidas de letras diferentes, na linha, diferem entre si pelo teste de SNK, a 5\% de probabilidade. ${ }^{(2)}$ Lignina em permanganato de potássio. 
O ganho médio diário apresentou resposta quadrática à oferta e foi crescente até a oferta de $11,7 \%$, quando atingiu o máximo de $0,852 \mathrm{~kg}$ por dia (Figura 3 ). O ganho médio diário está relacionado a vários fatores: no que se refere à pastagem, à quantidade e à qualidade da forragem aos animais; e às oportunidades que algumas ofertas de folhas permitem ao animal de desfrutar um pastejo seletivo. Apesar de não terem sido observadas diferenças significativas na qualidade da forragem, com exceção da menor oferta, uma maior disponibilidade de forragem permite ao animal selecionar uma dieta com melhor qualidade (Bailey et al., 1996).

Respostas quadráticas entre ganho médio diário e oferta foram obtidas por Almeida et al. (2000b), com pastagem de capim-elefante anão cultivar Mott, por Soares et al. (2005), com pastagem nativa, e por Barbosa et al. (2006), com capim-tanzânia. Num período mais curto de avaliação, Andrade (2003) observou resposta linear do ganho médio diário às alturas do dossel forrageiro de 10, 20, 30 e $40 \mathrm{~cm}$, em pastagem de Brachiaria brizantha cultivar Marandu. Este autor observou que o ganho médio diário foi conseqüência das alturas do dossel, e as variações no consumo foram determinadas pelas características físicas e não químicas da forragem em oferta. Sarmento (2003) observou que características do dossel forrageiro determinaram os padrões de comportamento ingestivo dos animais. Além da oferta de forragem, o ganho médio diário pode estar relacionado a variáveis como a altura do dossel e a massa de forragem (Andrade, 2003;

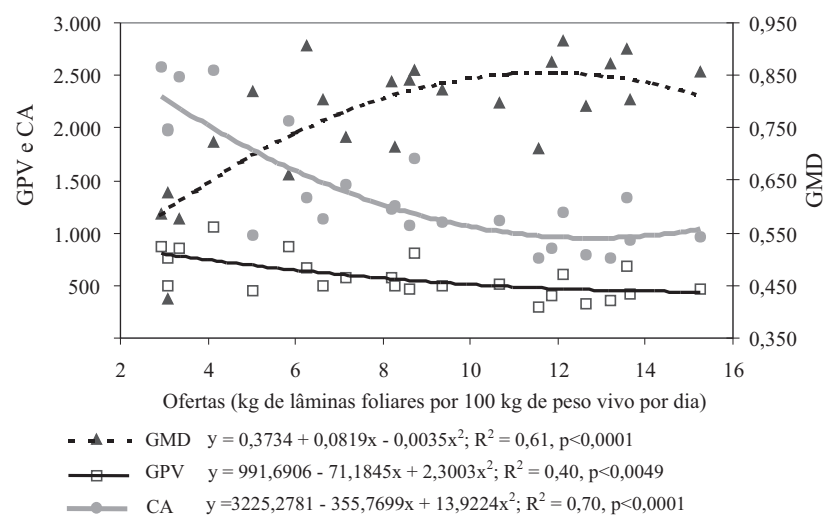

Figura 3. Ganho de peso vivo (GPV, $\mathrm{kg} \mathrm{ha}^{-1}$ ), carga animal $\left(\mathrm{CA}, \mathrm{kg} \mathrm{ha}^{-1}\right)$ e ganho médio diário (GMD, $\mathrm{kg}_{\text {animal }}{ }^{-1} \mathrm{dia}^{-1}$ ) de animais, em pastagem de capim-marandu, submetida a ofertas de lâminas foliares, nas estações das águas de 2002/2003, 2003/2004 e 2004/2005.
Missio et al., 2006). Outros resultados foram relatados por Postiglioni (2000) e Zervoudakis et al. (2002), que obtiveram com $B$. brizantha cultivar Marandu, no período das águas, ganho médio diário de $0,607 \mathrm{e}$ $0,708 \mathrm{~kg}$ por animal, respectivamente.

A carga animal apresentou relação quadrática com as ofertas e variou de 2.283 a $1.021 \mathrm{~kg} \mathrm{ha}^{-1}$ de peso vivo com relação às ofertas de 3 e $15 \%$ do peso vivo, respectivamente. Estes resultados corroboram os de Almeida et al. (2000b), que avaliaram capim-elefante anão Mott e obtiveram relação quadrática entre a carga animal e a oferta. Resultado semelhante foi obtido por Andrade (2003), em que a taxa de lotação em pastagem de capim-marandu decresceu com o aumento da altura do dossel forrageiro.

O ganho por hectare apresentou resposta quadrática ao aumento da oferta de lâminas foliares verdes, que diminuiu de 799 para $441 \mathrm{~kg} \mathrm{ha}^{-1}$ nas ofertas de $3 \mathrm{e}$ $15 \%$, respectivamente. Tendência quadrática também foi obtida por Barbosa et al. (2006), com capimtanzânia, quando avaliaram ofertas de matéria seca de lâminas foliares verdes de 3 a 15\% do peso vivo.

Apesar de as menores ofertas propiciarem maior ganho por hectare, na estação das águas, esse resultado não pode ser considerado isoladamente. No presente trabalho, não foi possível avaliar o desempenho dos animais durante a estação seca, mas deve-se considerar que a massa de forragem foi crescente, proporcional ao aumento da oferta. De acordo com Barbosa et al. (2006), este maior ganho com a oferta mais baixa poderia levar à hipótese de maior retorno econômico, porém, esse manejo resulta em menor massa de forragem, o que pode levar os animais a perdas de peso durante a estação seca (inverno). Estes autores observaram, durante a estação seca, perdas de $0,16 \mathrm{~kg}$ por animal por dia a ganhos de $0,22 \mathrm{~kg}$ por animal por dia, nas ofertas de lâminas foliares verdes de 3 e $11 \%$ do peso vivo, respectivamente.

O ganho por animal é tão importante quanto o ganho por hectare e está relacionado à velocidade de terminação dos animais e ao giro de capital. Os resultados do presente trabalho foram obtidos numa condição experimental com ajuste mensal da carga animal. Num sistema de produção, a possibilidade de se variar a taxa de lotação é pequena e, portanto, é necessário que o produtor faça o planejamento de suas 
atividades com margem de segurança razoável, para assegurar que os animais estejam terminados naquele ano agrícola.

As informações obtidas neste trabalho são úteis aos agropecuaristas que fazem a recria e engorda de bovinos. Com exceção da menor oferta, os animais atingiram o peso mínimo exigido pelos frigoríficos para o abate - de $450 \mathrm{~kg}$ - (Figura 4), no início da estação seca, antes de completarem 24 meses de idade. Nas ofertas superiores a $7 \%$, foi possível fazer a recria e a engorda de parte dos animais, num período aproximado de 12 meses.

Os animais traçadores mantidos na oferta de $4 \%$ apresentaram, ao término da estação de crescimento, 50 a $60 \mathrm{~kg}$ menos do que aqueles mantidos nos demais tratamentos. Tal diferença representa muito, quando a estação seguinte é a seca, na qual há, normalmente, menor disponibilidade de forragem. Para a terminação de animais com $400 \mathrm{~kg}$, que foi o peso médio dos animais submetidos à menor oferta, são necessários, em regime de pastejo, de seis a oito meses. Portanto, mesmo que na menor oferta o ganho por área seja maior, não se justifica a sua utilização porque, além do prejuízo à pastagem, há redução considerável no desempenho dos animais, e aumento do tempo necessário para as fases de recria e engorda em pasto. A demora no retorno do capital investido é um dos grandes problemas na pecuária, quando comparada a outras atividades.

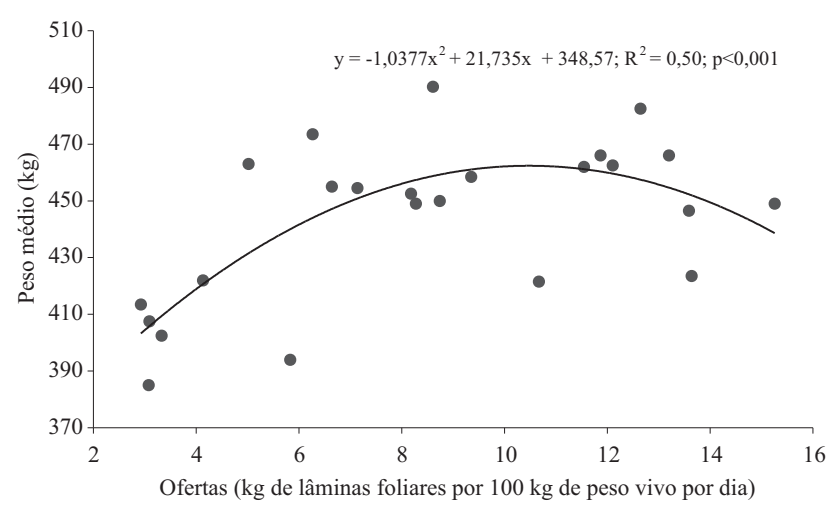

Figura 4. Peso médio final dos animais, em junho de 2003, 2004 e 2005, submetidos a ofertas de lâminas foliares, em pastagem de capim-marandu.

\section{Conclusão}

As ofertas de 8 a $12 \%$ do peso vivo permitem que os animais consumam as folhas verdes, com qualidade da dieta em proteína bruta, digestibilidade in vitro da matéria orgânica, fibra em detergente neutro e menor ingestão de lignina; este manejo permite a terminação de novilhos aos 24 meses de idade.

\section{Agradecimentos}

À Fundação de Apoio ao Desenvolvimento do Ensino, Ciência e Tecnologia do Estado do Mato Grosso do Sul, pelo apoio financeiro; ao Sr. Nestor Ivo Bocchi, pelo fornecimento dos animais para o experimento; ao Médico Veterinário Elton Bock Corrêa, pela colaboração na realização deste trabalho.

\section{Referências}

ALMEIDA, E.X. de; MARASCHIN, G.E.; HARTHMANN, O.E.L.; RIBEIRO FILHO, H.M.N.; SETELICH, E.A. Oferta de forragem de capim-elefante anão 'Mott' e a dinâmica da pastagem. Revista Brasileira de Zootecnia, v.29, p.1281-1287, 2000a.

ALMEIDA, E.X. de; MARASCHIN, G.E.; HARTHMANN, O.E.L.; RIBEIRO FILHO, H.M.N.; SETELICH, E.A. Oferta de forragem de capim-elefante anão 'Mott' e o rendimento animal. Revista Brasileira de Zootecnia, v.29, p.1288-1295, 2000b.

ANDRADE, F.M.E. de. Produção de forragem e valor alimentício do capim-marandu submetido a regimes de lotação contínua por bovinos de corte. 2003. 125p. Dissertação (Mestrado) - Escola Superior de Agricultura Luiz de Queiroz, Piracicaba.

ASSOCIATION OF OFFICIAL ANALYTICAL CHEMISTS. Official methods of analysis of the Association of Official Analytical Chemists. $15^{\text {th }}$ ed. Washington: AOAC, 1990.

BAILEY, D.W.; GROSS, J.E.; LACA, E.A.; RITTENHOUSE, L.R.; COUGHENOUR, M.B.; SWIFT, D.M.; SIMS, P.L. Mechanisms that result in large herbivore grazing distribution patterns. Journal of Range Management, v.49, p.386-400, 1996.

BARBOSA, M.A.A. de F.; NASCIMENTO JUNIOR, D. do; CECATO, U. Dinâmica da pastagem e desempenho de novilhos em pastagem de capim-tanzânia sob diferentes ofertas de forragem. Revista Brasileira de Zootecnia, v.35, p.1594-1600, 2006.

BARCELLOS, A. de O. Sistemas extensivos e semi-intensivos de produção: pecuária bovina de corte nos Cerrados. In: SIMPÓSIO SOBRE O CERRADO, 8.; INTERNATIONAL SYMPOSIUM ON TROPICAL SAVANNA, 1., Brasília, 1996. Biodiversidade e produção sustentável de alimentos e fibras no Cerrado: anais. Planaltina: Embrapa-CPAC, 1996. p.130-136.

DALLEY, D.E.; ROCHE, J.R.; GRAINGER, C.; MOATE, P.J. Dry matter intake, nutrient selection and milk production of dairy cows grazing rainfed perennial pastures at different herbage allowances 
in spring. Australian Journal of Experimental Agriculture, v.39, p.923-931, 1999.

DOYLE, P.T. Supplements other than forages. In: HACKER, J.B.; TERNOUTH, J.H. (Ed.). The nutrition of herbivores. New York: Academic Press, 1987. p.429-464.

FORBES, T.D.A.; HODGSON, J. Comparative studies of the influence of sward conditions on the ingestive behaviour of cows and sheep. Grass and Forage Science, v.40, p.69-77, 1985.

GIBB, M.J.; TREACHER, T.T. The effect of herbage allowance on herbage intake and performance of lambs grazing perennial ryegrass and redclover swards. Journal of Agricultural Science, v.86, p.355-365, 1976.

GOERING, H.K.; VAN SOEST, P.J. Forage fiber analyses (apparatus, reagents, procedures and some applications). Washington: USDA, 1970. 20p. (Agricultural Handbook, 379).

GRABBER, J.H. How do lignin composition, structure, and cross-linking affect degradability? A review of cell wall model studies. Crop Science, v.45, p.820-831, 2005.

HAYDOCK, K.P.; SHAW, N.H. The comparative yield method for estimating dry matter yield of pasture. Australian Journal of Experimental Agriculture and Animal Husbandry, v.15, p.663-670, 1975.

HERINGER, I.; CARVALHO, P.C. de F. Ajuste da carga animal em experimentos de pastejo: uma nova proposta. Ciência Rural, v.32, p.675-679, 2002.

HODGSON, J. Sward conditions, herbage allowance and animal production: an evaluation of research results. Proceedings of New Zealand Society of Animal Production, v.44, p.99-104, 1984.

KEMPTON, T.J.; LENG, R.A. Protein nutrition of growing lambs. 1. Responses in growth and rumen function to supplementation of a low-protein cellulosic diet with either urea, casein and formaldehyde-treated casein. British Journal of Nutrition, v.42, p.289-302, 1979.

MACHADO, L.A.M.; FABRÍCIO, A.C.; ASSIS, P.G.G. de; MARASCHIN, G.E. Estrutura do dossel em pastagens de capimmarandu submetidas a quatro ofertas de lâminas foliares. Pesquisa Agropecuária Brasileira, v.42, p.1495-1501, 2007.

MACHADO, L.A.M.; KICHEL, A.N. Ajuste de lotação no manejo de pastagens. Dourados: Embrapa Agropecuária Oeste, 2004. 55p. (Embrapa Agropecuária Oeste. Documentos, 62).

MARASCHIN, G.E.; MOTT, G.O. Resposta de uma complexa mistura de pastagem tropical a diferentes sistemas de pastejo. Pesquisa Agropecuária Brasileira, v.24, p.221-227, 1989.

MERTENS, D.R. Methods in modeling feeding behavior and intake in herbivores. Annales de Zootechnie, v.45, p.153-164, 1996.

MISSIO, R.L.; BRONDANI, I.L.; MENEZES, L.F.G. de; ARBOITTE, M.Z.; ALVES FILHO, D.C.; RESTLE, J.; LEITE, D.T.; PIZZUTI, L.A.D. Massa de lâminas foliares nas características produtivas e qualitativas da pastagem de capim-elefante Pennisetum purpureum, Schum. (cv. Taiwan) e desempenho animal. Ciência Rural, v.36, p.1243-1248, 2006.

MOTT, G.O.; LUCAS, H.L. The design, conduct and interpretation of grazing trials in cultivated and improved pastures. In: INTERNATIONAL GRASSLAND CONGRESS, 6., 1952,
Pasadena. Proceedings. Pasadena: Pennsylvania State College Press, 1952. p.1380-1385.

MULLER, M.M.L.; GUIMARÃES, M. de F.; DESJARDINS, T.; MARTINS, P.F. da S. Degradação de pastagens na Região Amazônica: propriedades físicas do solo e crescimento de raízes. Pesquisa Agropecuária Brasileira, v.36, p.1409-1418, 2001.

NATIONAL RESEARCH COUNCIL. Nutrient requirements of beef cattle. $7^{\text {th }}$ ed. Washington: National Research Council, 1996. 242p.

PERON, J.A.; EVANGELISTA, A.R. Degradação de pastagens em regiões de Cerrado. Ciência e Agrotecnologia, v.28, p.655-661, 2004.

POPPI, D.P.; HUGLES, T.P.; L`HUILLIER, P.J. Intake of pasture by grazing ruminants. In: NEW ZEALAND SOCIETY OF ANIMAL SCIENCE. Livestock feeding pasture. Hamilton: New Zealand Society of Animal Production, 1987. p.55-64.

POSTIGLIONI, S.R. Avaliação de sete gramíneas de estação quente para produção de carne nos Campos Gerais do Paraná. Pesquisa Agropecuária Brasileira, v.35, p.631-637, 2000.

SARMENTO, D.O. de L. Comportamento ingestivo de bovinos em pastos de capim-marandu submetidos a regimes de lotação contínua. 2003. 76p. Dissertação (Mestrado) - Escola Superior de Agricultura Luiz de Queiroz, Piracicaba.

SOARES, A.B.; CARVALHO, P.C. de F.; NABINGER, C.; SEMMELMANN, C.; TRINDADE, J.K. da; GUERRA, E.; FREITAS, T.S. de; PINTO, C.E.; FONTOURA JUNIOR, J.A.; FRIZZO, A. Produção animal e de forragem em pastagem nativa submetida a distintas ofertas de forragem. Ciência Rural, v.35, p.1148-1154, 2005.

SOLLENBERGER, L.E.; MOORE, J.E. Assessing forage allowance-animal performance relationships on grazed pasture. Agronomy Abstracts, p.140-141, 1997.

SOLLENBERGER, L.E.; MOORE, J.E.; ALLEN, V.G.; PEDREIRA, C.G.S. Reporting forage allowance in grazing experiments. Crop Science, v.45, p.896-900, 2005.

SYSTAT SOFTWARE. SIGMAPLOT: version 8.02. Chicago: Systat Software, 2002.

TILLEY, J.M.A.; TERRY, R.A. A two-stage technique for the in vitro digestion of forage crops. Grass and Forage Science, v.18, p.104-111, 1963.

TRINDADE, J.K. da; SILVA, S.C. da; SOUZA JUNIOR, S.J. de; GIACOMINI, A.A.; ZEFERINO, C.V.; GUARDA, V.D.A.; CARVALHO, P.C. de F. Composição morfológica da forragem consumida por bovinos de corte durante o rebaixamento do capimmarandu submetido a estratégias de pastejo rotativo. Pesquisa Agropecuária Brasileira, v.42, p.883-890, 2007.

VAN SOEST, P.J. Nutritional ecology of the ruminant. $2^{\text {nd }} e d$. Ithaca: Comstock Pub., 1994. 476p.

ZERVOUDAKIS, J.T.; PAULINO, M.F.; DETMANN, E.; VALADARES FILHO, S. de C.; LANA, R. de P.; CECON, P.R. Desempenho de novilhas mestiças e parâmetros ruminais em novilhos, suplementados durante o período das águas. Revista Brasileira de Zootecnia, v.31, p.1050-1058, 2002. (Suplemento).

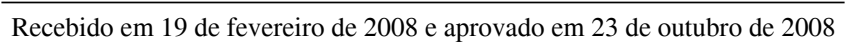

